\title{
William MacAskill, Krister Bykvist, and Toby Ord: Moral Uncertainty
}

\author{
Oxford: Oxford University Press, 2020. Hardback \\ (ISBN 978-0198722274) £ 50.00. 240 Pp.
}

\author{
Jiwon $\operatorname{Kim}^{1}$
}

Accepted: 9 July 2021/ Published online: 10 August 2021

(C) The Author(s) 2021

Keywords Moral decision-making · Expected choice-worthiness · Intertheoretic comparisons · Credence $\cdot$ Rationality

Many moral matters are uncertain. For example, it is indeterminate what degree of risk it is morally permissible to subject someone to, for how much benefit to others. If it is inevitable that we do not and cannot know all relevant moral facts, how are we to make a better moral decision when there is a risk of doing something morally wrong? William MacAskill, Kryster Bykvist, and Toby Ord's book, Moral Uncertainty (2020), make an important contribution to a field that has not been much investigated. In just over 200 pages with 9 chapters, MacAskill, Bykvist, and Ord (henceforth MBO) successfully packed the book with complex technicalities and dense arguments. The reader might have to be somewhat familiar with statistics and decision theory to understand all of their arguments, so this might not be suitable for those who are looking for an introductory book on moral uncertainty.

In chapter 1, MBO want us to consider the following case: Anne and Charlotte are suffering from the same medical condition. Both patients will die if they do not receive any treatment, and Susan has a drug that can help. If she administers it to Anne, Anne will survive but with a disability, at half the level of welfare she'd have if healthy. If Susan administers the drug to Charlotte, Charlotte would be completely cured because she is a chimpanzee. If Susan splits the drug between the two, then they will both survive, but Anne will be slightly worse off receiving half the drug than she would be receiving all of it. Given that Susan thinks that it is "equally likely" that chimpanzees' welfare has no moral value and that chimpanzees' welfare has the same moral value as human welfare, she would be risking severe wrongdoing by choosing to give the drug to either Anne or Charlotte. Therefore, she should split the drug, taking both theories into account.

Jiwon Kim

jiwon.kim@fil.lu.se

1 Lund University, Box 192, 22100 Lund, Sweden 
The interesting conclusion MBO draw from the example above is that, under moral uncertainty, we might end up choosing an option that is not recommended by the theory we have the most credence to. Their reasoning is the following: Theory A recommends alternative $\mathrm{x}$ over alternative $\mathrm{y}$, but only by a small margin. By contrast, Theory B recommends y by a very large margin. Even though it might be that our credence relative to $\mathrm{A}$ is higher than to $\mathrm{B}$, sometimes, it is morally less risky to do what B recommends as a result of the expected choiceworthiness calculation. Therefore, under moral uncertainty, a morally conscientious agent might have to choose an option they believe to be not credible. No matter how low or high one's credence is towards a theory, what one should do is determined by the expected choiceworthiness of the alternatives, and that this in turn is, in part, determined by the theories to which one is willing to assign some credence. Even though it is unintuitive that one might end up choosing an option that is recommended by the theory in which they have very low credence, $\mathrm{MBO}$ argue that this is what one must rationally do under moral uncertainty.

In chapters 3 and 4, MBO provide us with one of the book's core contributions: a method to compare the degree of choice-worthiness functions from different moral theories so that we will be able to conclude something like "Taking both theories into consideration, $\mathrm{x}$ is more choiceworthy than y." One should use the Borda Rule (i.e., the theories should rank options in order of preference, giving the most choice-worthy option to the option with most points) if the decision-maker has non-zero credence only in moral theories that are non- comparable to each other and not interval-scale measurable.

On the other hand, if the decision-maker has non-zero credence in moral theories that are interval-scale measurable and non-comparable to each other, one should use 'variance voting' instead. Variance voting treats the choice-worthiness variance as the same across all theories by normalising the theories according to their z-scores, assuming the choice-worthiness mean to be 0 . MBO argue that, only with variance voting, every theory gets to have equal say. One of the advantages of variance voting is that the variance of an ordinal-scale measurable moral theory can be normalised to the variance of an interval-scale measurable moral theory, enabling inter-theoretic comparisons between ordinal and cardinal theories.

In chapters 5 and 6, MBO argue against sceptics, structuralists, and fanatics. While sceptics think that choice-worthiness differences cannot be compared across moral theories, they fail to explain why many decision-makers have intuitions about inter-theoretic comparisons in many cases. On the other hand, structuralists believe that inter-theoretic comparisons are possible as long as there is one and only one common arbitrary unit that represents structural features of the theories' qualitative choice-worthiness relation. Even though there are many other ways that moral theories can be compared to each other (e.g., their metaphysical underpinnings or their relationship to epistemic reasons) structuralists fail to suggest a different factor that could normalise moral theories. Lastly, even though the worry from fanaticism resembles Pascal's wager (i.e., the options with fanatically high stakes or risks would swamp one's decisionmaking), MBO suggest that one should use the Borda Rule to aggregate our uncertainty over these fanatic options.

Expanding their argument to metaethics and practical ethics in the following chapters, MBO show in chapter 7 that while cognitivism can easily make sense of moral uncertainty, non-cognitivism cannot. In chapter 8, considering cases from abortion and vegetarianism, $\mathrm{MBO}$ argue that considerations of moral uncertainty should have major impacts on our moral decision-making and how practical ethics is conducted.

One might think that MBO's solution to moral uncertainty is very theory-centred. Unless the decision-maker is already familiar with some of the moral theories, such as utilitarianism 
and deontology, one would not be able to assign credences to these theories. This is why, in chapter 9, they suggest that we should spend a lot of time or available resources to gain and possess accurate moral information, such as experiences, arguments, intuitions, or knowledge of moral facts that should change some of our beliefs.

Whether or not we have reservations as to whether we should outsource our moral decisionmaking to this decision-theoretic procedure to which we have low credence (and I have some such qualms), the book is a worthwhile read for those who are interested in a rigorous method helping us to decide under conditions of moral uncertainty.

Funding Open access funding provided by Lund University.

Open Access This article is licensed under a Creative Commons Attribution 4.0 International License, which permits use, sharing, adaptation, distribution and reproduction in any medium or format, as long as you give appropriate credit to the original author(s) and the source, provide a link to the Creative Commons licence, and indicate if changes were made. The images or other third party material in this article are included in the article's Creative Commons licence, unless indicated otherwise in a credit line to the material. If material is not included in the article's Creative Commons licence and your intended use is not permitted by statutory regulation or exceeds the permitted use, you will need to obtain permission directly from the copyright holder. To view a copy of this licence, visit http://creativecommons.org/licenses/by/4.0/.

\section{Reference}

MacAskill W, Bykvist K, Ord T (2020) Moral uncertainty. Oxford University Press

Publisher's Note Springer Nature remains neutral with regard to jurisdictional claims in published maps and institutional affiliations. 